\title{
Summary of the 2002 CAG strategic planning survey
}

Philip M Sherman MD FRCPC, President, CAG

Sandra M Daniels MSc, CAG National Office

Richard N Fedorak MD FRCPC, Past President, CAG

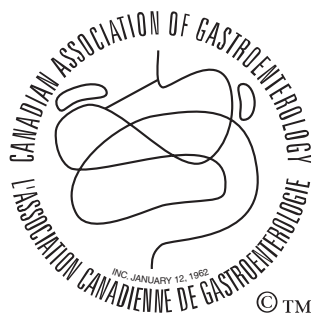

En français voir page 59

In this Journal, we have recently highlighted the progress of the Canadian Association of Gastroenterology (CAG) in meeting the goals and objectives outlined in the first Strategic Plan developed in 1993 (1). In September 2002, a Strategic Planning survey was mailed to all members of the CAG (a copy of the cover letter and survey are present for viewing on the CAG Web site <www.cag-acg.org/whatsnew/strat_plann_surv.htm>). The results of the responses to this survey were collated and presented to the Past Presidents of the CAG at a retreat held during the summer of 2003. These findings were then employed to develop a Strategic Plan for the CAG to guide its progress and development over the next five to ten years. A subsequent issue of this Journal will include a presentation of the CAG 2004 Strategic Plan, which was finalized and approved by the CAG Governing Board during the annual fall meeting in October 2003.

The Strategic Planning survey was returned to the National Office by 188 members of the CAG. A set of slides that provides a detailed summary of the entire survey is presented on the CAG Web site. A more abbreviated synopsis is provided here for your consideration.

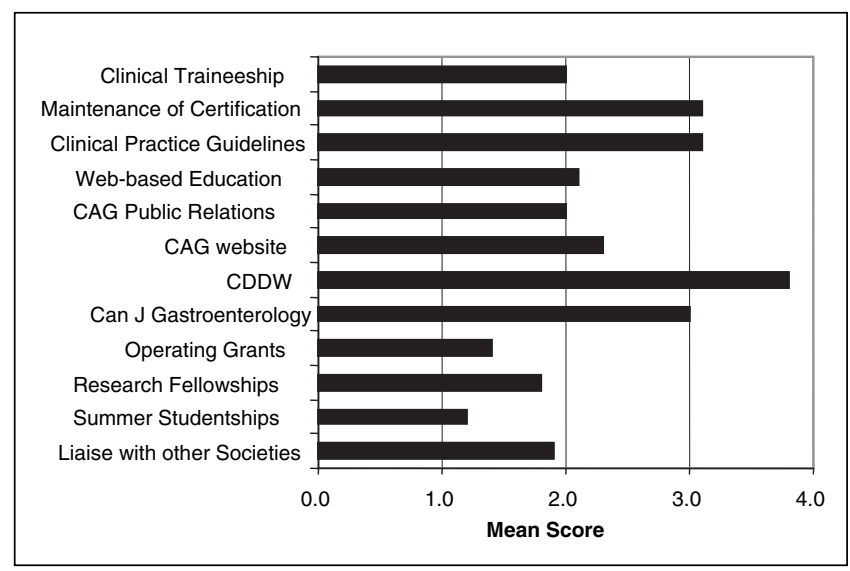

Figure 1) This figure presents the mean values of responses to "how important are these member benefits and services to you?" The scale used in the survey ranked from -5 (not important at all) to +5 (very important). CAG Canadian Association of Gastroenterology; CDDW Canadian Digestive Diseases Week
Figure 1 presents a summary of the services and benefits valued by the members. Continuing medical education activities, in general, and the Canadian Journal of Gastroenterology and the Canadian Digestive Diseases Week (Figure 2), in particular, are highly valued by our membership. The third figure (Figure 3) shows differences between perceived and desired strengths in a variety of areas. The findings indicate that the CAG is strong in education and research arenas, but highlight important gaps

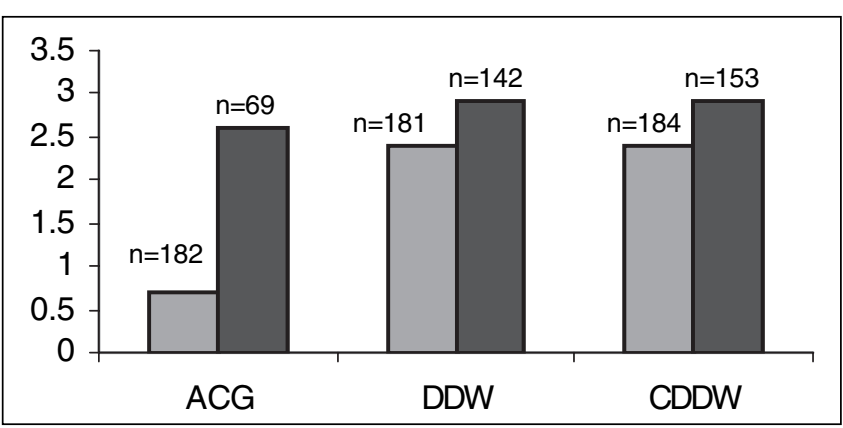

Figure 2) This figure presents the number of times respondents attended annual meetings in the last five years (light bar histograms) and the usefulness of the meetings (dark bars). The scale used in the survey ranked from -5 (not at all useful) to +5 (extremely useful). Numbers above each bar denotes the number of responses. ACG American College of Gastroenterology; DDW Digestive Disease Week; CDDW Canadian Digestive Diseases Week

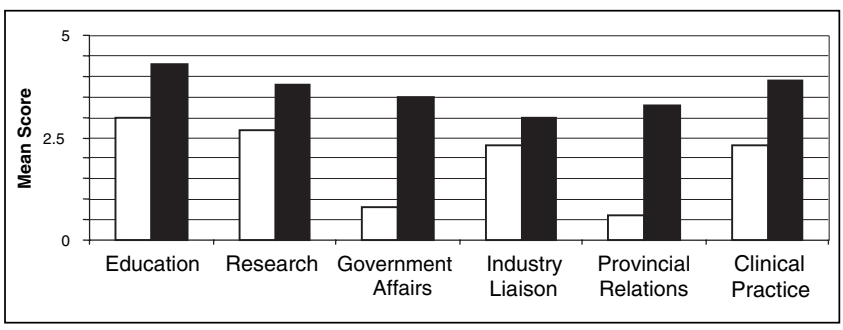

Figure 3) The findings in this figure reflect current (open bars) and desired (solid bars) influence when members were asked "how strong a role does or should the CAG exert in the following areas?" The scale used in the survey ranked from -5 (not strong at all) to +5 (very strong). CAG Canadian Association of Gastroenterology 


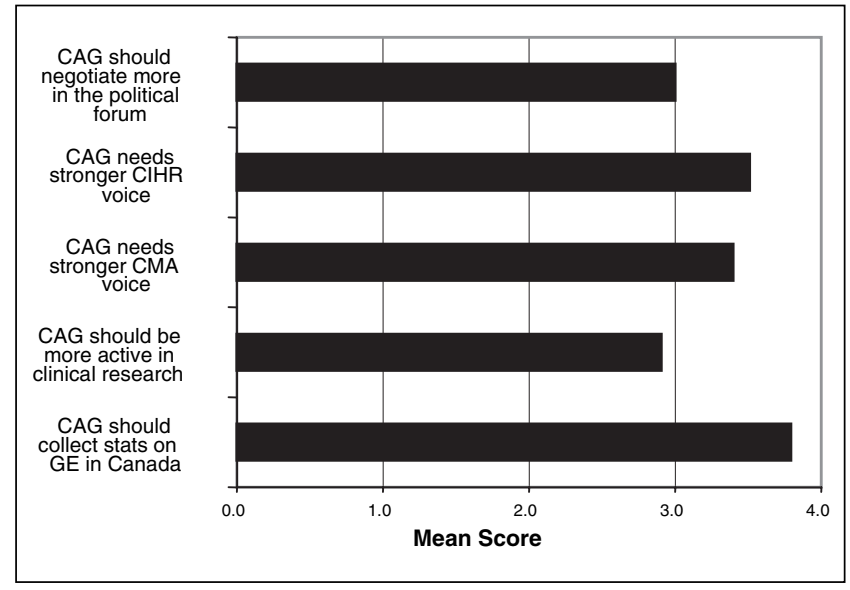

Figure 4) The role of the Canadian Association of Gastroenterolgoy (CAG) in policy making is considered in this figure. The scale used in the survey ranked from -5 (strongly disagree) to +5 (strongly agree). CIHR Canadian Institutes of Health Research; CMA Canadian Medical Association; GE Gastroenterology

related to issues of advocacy, lobbying, and our relationships with other societies and organizations.

As shown in Figure 4, there is strong support for the CAG to become more involved in issues of advocacy with a variety of partners, including provincial and federal governments, national funding agencies and national medical specialty societies. Figure 5 indicates the areas ranked by members of the CAG as high priority items warranting CAG time, energy and resources in the future. These issues formed the basis of the discussions undertaken to develop a new CAG Strategic Plan, which will be presented to you in these pages in the near future.

We very much welcome comments and feedback regarding the results and analysis of the 2002 Strategic Planning survey,

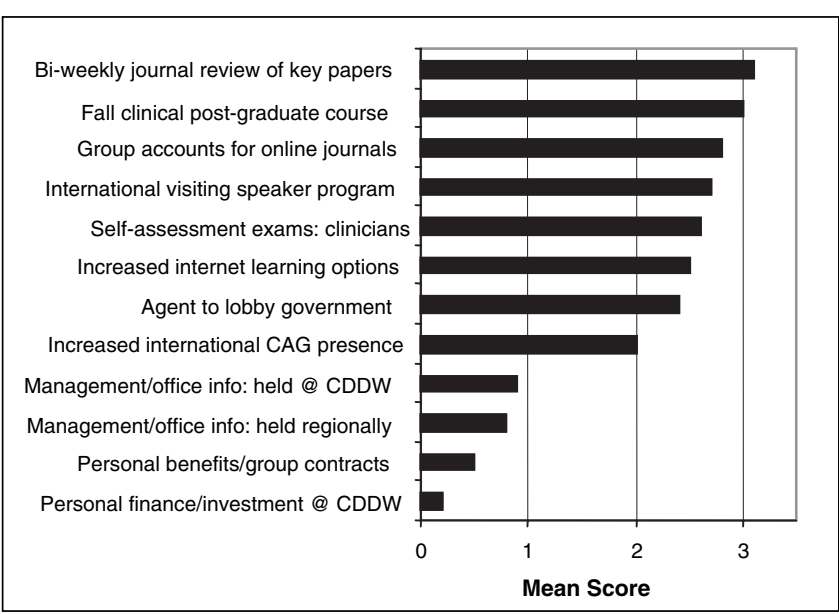

Figure 5) This figure provides a summary of responses to potential new Canadian Association of Gastroenterology (CAG) initiatives in a variety of areas. The scale used in the survey ranked from -5 (extremely unimportant) to +5 (extremely important). CDDW Canadian Digestive Diseases Week

which can be forwarded to the CAG National Office at CAGOffice@cag-acg.org. The CAG leadership values your input and insights. The future development of the organization relies upon the collective enthusiasm and support of all members of the CAG from across the nation.

ACKNOWLEDGEMENT: The CAG would like to acknowledge the unrestricted support of our partners AstraZeneca Canada Inc, Pentax Precision Instruments Corp and Schering Canada Inc for the CAG Past Presidents Council Strategic Planning meeting.

\section{REFERENCE}

1. Fedorak R, Sherman P. The 1993 Canadian Association of

Gastroenterology Strategic Plan: Excellence in Achievement.

Can J Gastroenterol 2003;17:683-4. 


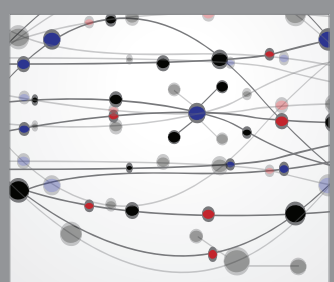

The Scientific World Journal
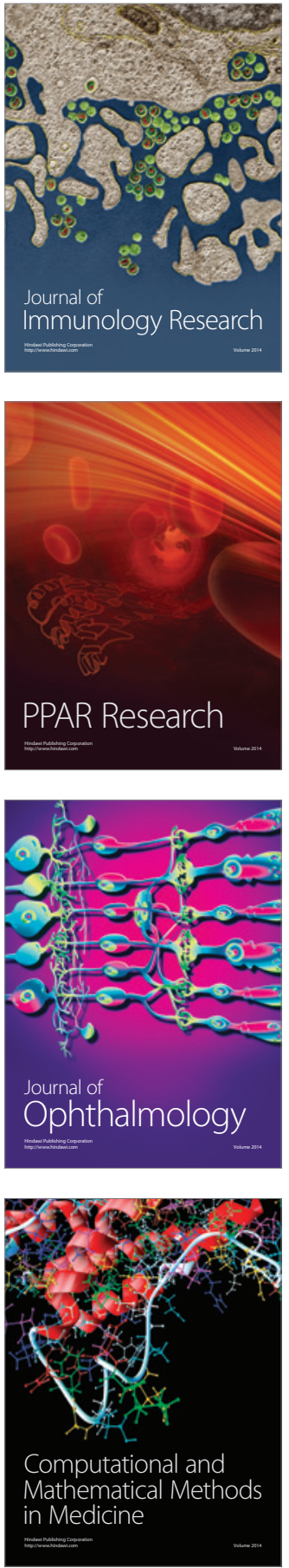

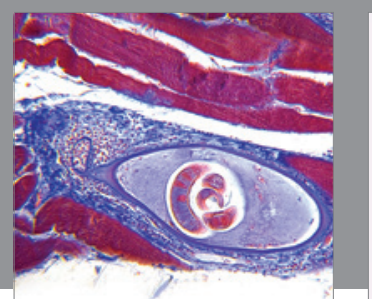

Gastroenterology Research and Practice

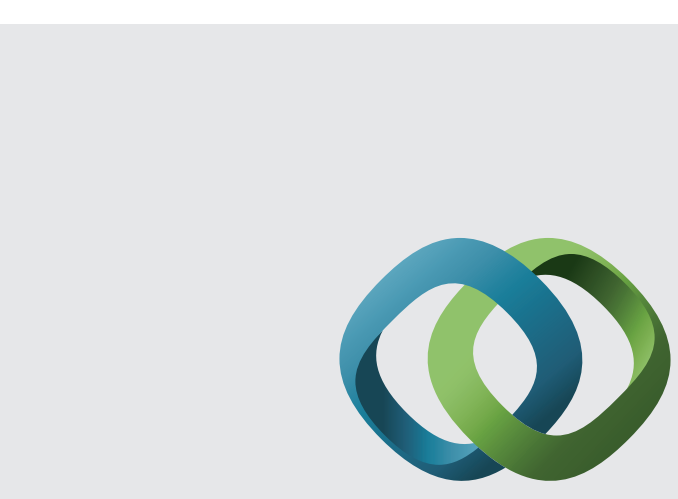

\section{Hindawi}

Submit your manuscripts at

http://www.hindawi.com
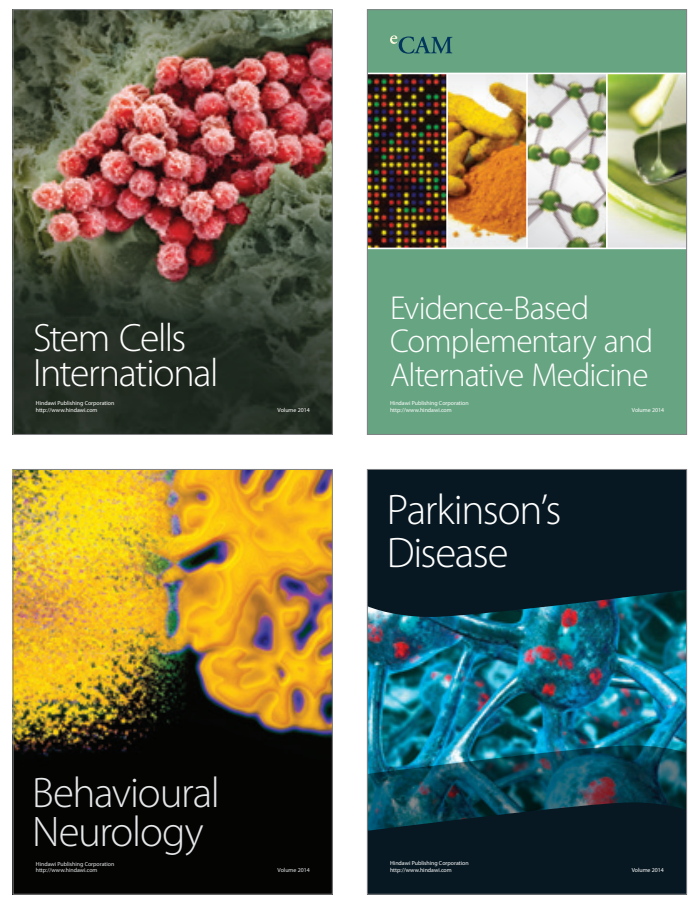
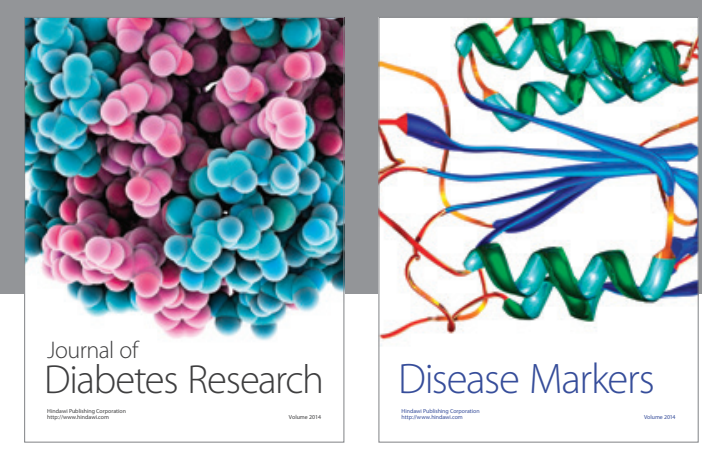

Disease Markers
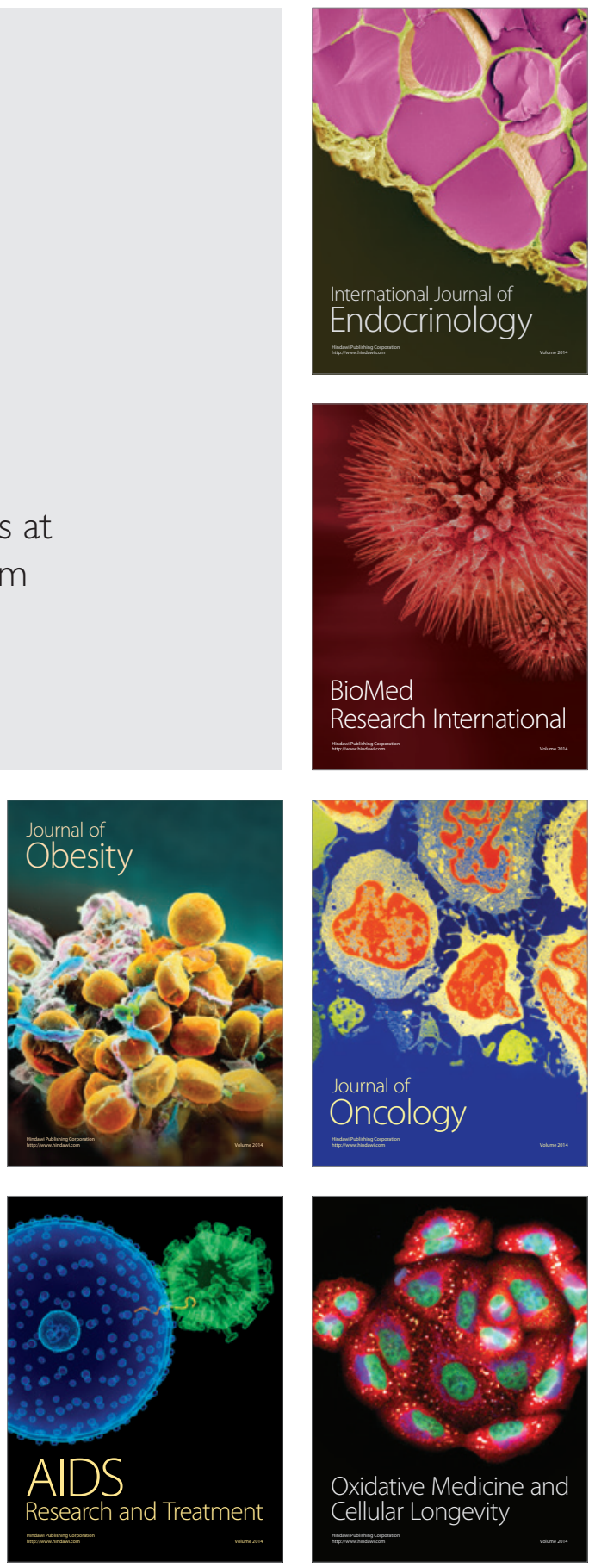